\title{
The Concept of Déprise
}

ISSN: 2578-0093

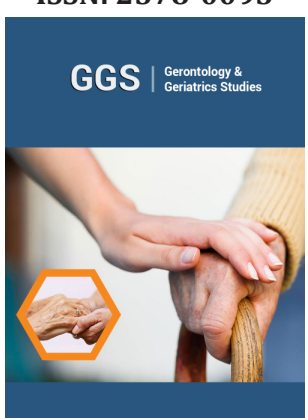

*Corresponding author: Anastasia Meidani, research professor at the University of Toulouse II Jean Jaurès Department of Sociology Laboratory LISST UMR 5193 CNRS \& associated researcher INSERM U 1027, France

Submission: 悳 December 10, 2019

Published: 啙December 19, 2019

Volume 5 - Issue 4

How to cite this article: Anastasia Meidani. The Concept of Déprise. Gerontol \& Geriatric stud.5(4). GGS.000617.2019. DOI: 10.31031/GGS.2019.05.000617

Copyright@ Anastasia Meidani, This article is distributed under the terms of the Creative Commons Attribution 4.0 International License, which permits unrestricted use and redistribution provided that the original author and source are credited.

\author{
Anastasia Meidani* \\ Department of Sociology, France
}

\begin{abstract}
The purpose of this article is to enrich reflection on the experiences of ageing in the light of the concept of déprise, which is now authoritative in the field of gerontology in France. Initially déprise conceived as an analytical tool, making it possible to report on the experiences of ageing, déprise, according to those who conceived it, can be defined as a "process of reorganisation of life" which takes effect in the light of a previous life trajectory and a precise socio-cultural context.
\end{abstract}

Keywords: Experiences of ageing déprise

\section{Introduction}

The purpose of this article is to enrich reflection on the experiences of ageing in the light of the concept of déprise, which is now authoritative in the field of gerontology in France. Initially conceived as an analytical tool, making it possible to report on the experiences of ageing, déprise, according to those who conceived it [1-3], can be defined as a "process of reorganization of life" [2] which takes effect in the light of a previous life trajectory and a precise socio-cultural context. In France, the study of old age is marked by a biomedical conception of aging associated with economic, managerial and political concerns. This has led to the construction of a negative image of the process, which has been widely criticized by sociologists over the past twenty years [4-7]. Faced with this hegemonic model of thinking, déprise has helped to shift the focus of analysis and nuance approaches to aging. It has been shown that, since the middle of the $20^{\text {th }}$ century, the most optimistic interpretation of aging, based on the gain in life acquired, has been the injunction to "age well" $[8,9]$. This model and the injunctions it contains reveal the limits of a technicist form of thinking and bring to light the shortcomings of a reductionist, ageist and sexist approach to ageing.

But what about the analytical added value of the concept? A brief historical overview of the genesis of the paradigm attests to its analytical potential. In 1988, in their first text dedicated to déprise, Barthe, Clément and Drulhe sought to answer two major theories in social gerontology: activity [10] and disengagement [11]. It is mainly opposed to the second, differing from it in that it does not consider the aging process as a series of losses, a gradual decline leading to social withdrawal. On the contrary, the concept of déprise makes it possible to work on the individual experience of aging through a double process, one of losses and gains. Driven by this reflection, Clément and his colleagues, along with Mantovani, Drulhe, Membrado and Meidani, refined it and continued to develop the concept with data from stimulating sociological studies [1-3,8,12-15]. Beyond the Toulouse school, the paradigm was enthusiastically welcomed and taken up by other French researchers $[6,16,17]$.

As mentioned above, déprise can be characterized as a process of reorganization and adjustment of everyday life based on a series of attempts at the substitution of activities or relationships. These arise after various experiences of rupture (retirement, widow-or widowerhood, bereavement, institutional placement) or being faced with impossibility (as after an accident or fall), which accentuate the feeling of fragility and loss of control over the world, leading to the feeling that one is no longer able to accomplish what was possible when the forces were there. Within this work of negotiation and restructuring of oneself with oneself, with others and with the environment, which operates by selection and reorientation, people seek to avoid overtaxing themselves by experimenting by trial and error with what can still be accomplished. Such reconversion strategies, which aim to guarantee a certain economy of strength, are also a means of preserving the integrity of one's identity in the face of the irreversibility of time. 
Within this process, the individual proceeds by selection. One needs criteria in order to establish choices. The first criterion refers to body capital and the health pathway, which is smooth or fraught with obstacles and pitfalls. Here it is a question of focusing on the question of what is wanted, and of desire, which, freed from the constraints of the past, aims to ensure a certain taste for life, while taking into account the "vital energy" which diminishes with time [1] and is expressed, on the one hand, in the fatigue experienced by the most elderly and, on the other hand, in the awareness of the proximity of death. The second criterion involves relational and geographical proximity, which becomes intertwined with the principle of reciprocity [18]. A final criterion refers to the sociocultural context, understood both through public policies on old age and through various groups of affiliation.

Déprise highlights the lack of linearity in life pathways, where re-starts and holds over one (reprises et emprises) join hands [19]. By implementing strategies of accommodation, people proceed by anticipation: they economies their strength, avoid overtaxing themselves, reduce risk taking, or avoid activities that are considered secondary or too costly in terms of energy. In this sense, re-starting is a eulogy to the inventiveness deployed "to circumvent these obstacles and replace them with multiple openings" (13: 336-337). The point here is not to present re-starting as a "mirror response" to déprise, but to recall that the concept reflects the positive possibility that an individual has of adapting to aging. In other words, this process is not unambiguous: if aging is characterized by ruptures, it also implies re-starts (re-prizes), rebounds, and sometimes even processes that threaten the individual's control, the power of deciding their fate. Beyond the hold taken by disease, which often initiates that taken by institutions (institutional placement), the unequal profiles of seniors also dictate the terms of the experience of aging, giving way to forms of control that are essentially reserved for the most disadvantaged. As for the influence of others, which is reflected in interactions concerning care or subsidiary supportive relationships, it also sometimes undermines negotiated processes of withdrawal.

At the heart of this dynamic, which integrates plurality, déprise makes it possible to understand the various aspects of aging. Clément et al. [2] highlight distressed forms of déprise where the proximity of death becomes worrying. In these cases, the relationship with the family environment is often problematic and the feeling of no longer controlling one's own life choices leads to attitudes of withdrawal. Isolated from the world, the aging person feels that she or he no longer belongs to society and is no longer secure, a situation that is often accompanied by feelings of uselessness. The result is a negative world view that is expressed in forms of complaint, illustrating processes of déprise that are uncontrolled. Moreover, when the experience of aging is conditioned by the grip of serious and chronic illness, the déprises are often irreversible. Indicators of these déprises include signs of an altered relationship to time and space, as well as a strong tendency to disorientation (neurological disorders).
But what should be stressed here is that if there are losses, there can also be satisfaction, serenity and a sense of continuity. In such a context, the loss of control gives rise to reconfigurations that appear more as a rebound anchored in a process of selection of activities and relationships, most easily observed among elders who have the physical and material means, as well as relational ones. We thus see arising a concern for looking after oneself in order to be able to continue maintaining what seems most important. This impressive process is aimed at letting go of certain activities in order to remain fully engaged in others, considered more important, when professional constraints are no longer there, when children are no longer at home, from the point at which the disease is no longer heeded, etc.

\section{Conclusion}

a) If aging means adapting to the transformations brought about by the passage of time, at the heart of the accommodations that accompany aging the "will to do" is sometimes detached from "being able to do". But this experience, far from being disqualifying, testifies to the emergence of a distancing from things. In this context, it is a question of taking account of these "arts of doing" by questioning their inscriptions in time and space, the relationship to oneself and to others.

\section{References}

1. Barthe JF, Clément S, Drulhe M (1988) Old age or aging? Lifestyle organization processes in the elderly. Social Work Research Notebooks 15: 11-31.

2. Clément S, Mantovani J (1999) Departures at the end of their life course. The very last years of life. Gerontology and Society 90: 95-108.

3. Clément S, Membrado M (2010) Experiences of aging: genealogy (genesis) of the notion of abandonment. In: Carbonnelle S (Ed.), Thinking old people, Anthropological and sociological views on advancing age. Seli Arslan, Paris, France, pp. 109-128.

4. Clément S, Drulhe M, Durand D, Membrado M (1998) Forms and sense of aging. Prevent 35: 5-8.

5. Epinay CL, Bickel JF, Maystre C, Vollenwyder N (2000) Aging over time. 1979-1994: A quiet revolution. Social realities, Lausanne, Switzerland.

6. Caradec V (2004) Aging after retirement. Sociological approach to aging. University Press of France, Paris, France.

7. Charpentier M, Queniart A (2015) The cross-media effects of age, gender and migration on the body image of immigrant older women. Gerontology and Society 37 (148): 95-107.

8. Meidani A, Membrado $M$ (2011) Aging and aging: what health challenges? In: Drulhe M, Sicot F (Eds.) Open heart health. Sociology of well-being, disease and care Toulouse, University of the Midi Press, France, pp. 231-254.

9. Meidani A (2014) Alzheimer's disease, patients, and informal caregivers: Patterns of care in France, Sweden, and Greece. In: Leist AK, Kulmala J (Eds.), Health and cognition in old age: From biomedical and life course factors to policy and practice, Springer International Publishing, Cham, Switzerland, pp. 252-270.

10. Havighurst RJ, Albrecht R (1953) Older people New-York. London, Green and Co, Longmans, Toronto, Canada.

11. Cumming E, Henry WE (1961) Growing Old. The Process of Disengagement, Basic Books, New York, USA. 
12. Clément S (1994) The times of dying: Changes and permanence. International Sociology Notebooks XCVII: 1-12.

13. Drulhe M, Clément S, Mantovani J, Membrado M (2007) The neighborhood experience: general properties and specifics during old age. International notebooks on sociology 123(2): 325-339.

14. Meidani A, Cavalli S (2018) Living the aging: around the concept of abandonment. Gerontology and Society 1(40): 155.

15. Meidani A, Cavalli S (2019) Figures of Aging and Forms of Depreciation. Érès, Toulouse, France.
16. Mallon I (2004) Living in a retirement home. The last home. Presses Universitaires de Rennes, Rennes, France.

17. Pennec S, Claudic YG, Uguen FLB, Thomsin L (2001) Experience retirement, male and female. Diversified routes according to social affiliation. Gender notebooks 31: 81-104.

18. Mantovani J, Membrado M (2000) Experiences of old age and forms of aging. Social Information 88: 10-17.

19. Meidani A (2019) Losing your head, aging and dying: the experience of death in Alzheimer's patients in France, Greece and Sweden. In: Meidani A, Bousigue JY (Eds.), Vivre la mort, PUM (sauce press), Toulouse, France. 